\title{
IMPACTOS DA REFORMA TRABALHISTA NO MERCADO DE TRABALHO DE SANTA CATARINA
}

\author{
IMPACTS OF THE LABOR REFORM ON THE LABOR MARKET OF SANTA \\ CATARINA
}

\author{
Lauro Mattei ${ }^{1 *}$ \\ Vicente Loeblein Heinen ${ }^{2 * *}$
}

\begin{abstract}
RESUMO
O objetivo principal do artigo é analisar os impactos da reforma trabalhista efetuada no Brasil em 2017, sobre o mercado de trabalho de Santa Catarina. O ponto de partida analítico remonta ao processo de mudanças recentes no mundo do trabalho no âmbito global, bem como ao processo de crise econômica que se estabeleceu no país a partir de 2014. Tomando como base as informações da PNAD Contínua, são analisados os possíveis impactos das mudanças na legislação trabalhista sobre os níveis de ocupação da força de trabalho e de formalização do emprego no estado catarinense e, com base nos dados da Rais, sobre o mercado formal de trabalho do estado, articulando particularmente as modalidades do trabalho intermitente e do trabalho parcial. Os resultados indicam que, em vez de atacar a precarização, a reforma acabou facilitando sua extensão para áreas que antes forneciam um maior grau de segurança aos trabalhadores.
\end{abstract}

Palavras-chave: Santa Catarina, mercado de trabalho, reforma trabalhista.

\begin{abstract}
The main objective of the article is to analyze the impacts of the labor reform carried out in Brazil in 2017 on the labor market of Santa Catarina. The analytical starting point goes back to the recent process of changes in the world of work at the global level, as well as to the process of economic crisis established in the country from 2014. Based on information from PNAD Contínua, the article analyzes the possible impacts of changes in labor legislation over the levels of workforce occupation and formalization of employment in the state of Santa Catarina, and, based on Rais data, over the formal labor market, particularly the modalities of intermittent and part-time work. The results indicate that, instead of attacking labor precariousness, the reform facilitated its extension to areas that previously provided workers with a higher degree of security.
\end{abstract}

Keywords: Santa Catarina, labor market, labor reform.

\section{INTRODUÇÃO}

Para analisar adequadamente o comportamento do mercado de trabalho em períodos de crise econômica, torna-se necessário, incialmente, situar os parâmetros macroeconômicos dessa crise e seus distintos efeitos. Para tanto, é importante resgatar alguns traços gerais da

\footnotetext{
1* Professor Titular do Departamento de Economia e Relações Internacionais e do Programa de Pós-Graduação em Administração, ambos da UFSC e Pesquisador do OPPA/CPDA/UFRRJ. E-mail: l.mattei@ufsc.br.

2** Estudante do curso de Economia da UFSC. E-mail: vicenteheinen@gmail.com.
} 
economia brasileira na presente década como forma de estabelecer as devidas conexões entre os aspectos gerais da crise no país e seus efeitos particulares em âmbito estadual.

Como é amplamente conhecido, a economia brasileira teve um expressivo surto de crescimento entre 2003 e 2014, período em que o Produto Interno Bruto (PIB) se expandiu à taxa média de 3,4\% ao ano. Todavia, quando se analisa o período 2011-2014 separadamente (Governo Dilma I), é possível observar que a economia nacional já demonstrava sinais de crise, a qual se instalaria fortemente nos anos subsequentes. De um lado, a inflação já estava entrando em uma fase aceleracionista, ao passar de 5,8\% em 2012, para 6,4\% em 2014. Por outro lado, a atividade econômica esboçava uma desaceleração, com o PIB apresentando crescimento de apenas $0,5 \%$ em 2014. Como o governo continuou ampliando o gasto público, o superávit físcal caiu de 2,2\% do PIB em 2012, para - $0,6 \%$ em 2014, elevando o déficit em conta corrente como proporção do PIB para 3,9\% em 2014 (BCB, 2019).

É nesse cenário que Dilma foi reeleita presidente, com mandato previsto para o período 2015-2018. Sob o pretexto de combater a inflação e o avanço do déficit em transações correntes, ao longo de 2015 seu governo tentou implementar um plano de ajuste fiscal, coordenado pelo então Ministro da Fazenda, Joaquim Levy, o qual não obteve êxito nas negociações com o Congresso Nacional (CN). Com isso, a política econômica adotada no primeiro ano do segundo mandato da presidente Dilma não conseguiu evitar uma nova expansão do déficit primário, ao mesmo tempo em que não foi capaz de impedir uma escalada inflacionária, cujo patamar atingiu a cifra de $10,7 \%$ ao final do ano de 2015 .

Nesse contexto, a saída encontrada pelo governo foi a troca da equipe econômica ao final de 2015, porém sem esboçar qualquer capacidade de alteração do ambiente econômico. Para controlar a inflação, o Banco Central elevou continuamente a taxa básica de juros no biênio 2015-2016, o que afetou o desempenho das empresas. A consequência foi uma forte retração da taxa de investimentos da economia, com aumento da capacidade produtiva ociosa, especialmente no setor industrial. $O$ resultado final se traduziu em uma violenta recessão econômica, com variação do PIB da ordem de $-3,5 \%$ nos dois primeiros anos do período.

Esse cenário completou a degradação do capital político do Governo Dilma II, culminando no Impeachment que ocorreu em 2016 e que alçou seu vice, Michel Temer, à condição de Presidente da República. Apesar do discurso empresarial de que a mera troca de presidente solucionaria imediatamente a crise nacional, o Governo Temer foi marcado por um crescimento econômico pífio, com variação do PIB próximo a 1\% ao ano entre 2017 e 2018.

Os impactos desse cenário econômico recessivo foram expressivos sobre o mercado de trabalho. A taxa de desocupação, que era de apenas $6,5 \%$ ao final de 2014 , chegou a $13,7 \%$ no primeiro semestre de 2017, quando aproximadamente 13 milhões de pessoas se encontravam desempregadas (PNADC/T, 2019). Entre o final de 2014 e de 2017, houve um crescimento de $80 \%$ na taxa de desocupação e de $60 \%$ na taxa de subutilização da força de trabalho, além de um avanço acelerado da informalidade no emprego. Registre-se que esse contexto de elevados índices de desemprego e de informalidade foi utilizado como justificativa para a defesa da reforma trabalhista, aprovada em 2017 (MATTEI; HEINEN, 2019).

À luz desse cenário nacional, o presente artigo tem por objetivo analisar os impactos da reforma trabalhista sobre a dinâmica do mercado de trabalho no estado de Santa Catarina. Para tanto, o artigo está estruturado em mais cinco seções, além desta breve introdução. A primeira seção analisa brevemente as mudanças contemporâneas do mundo do trabalho, visando compreender os sentidos históricos da reforma trabalhista. A segunda seção sintetiza as principais alterações promovidas pela reforma trabalhista, identificando seus objetivos e 
suas supostas contrapartidas. A fim de observar se elas se concretizaram no estado catarinense, a terceira seção apresenta um panorama recente do mercado de trabalho em Santa Catarina, considerando o período entre 2014 e 2018. Já a quarta seção procura analisar em que nível as alterações legislativas promovidas pela reforma já podem ser observadas no mercado de trabalho catarinense, particularmente no que se refere às modalidades de trabalho intermitente e parcial. Finalmente, a quinta seção apresenta as considerações finais do estudo, destacando as principais tendências observadas.

\section{BREVES NOTAS SOBRE O MUNDO DO TRABALHO NO SÉCULO XXI}

No âmbito mundial, a origem das tendências atuais da organização do trabalho data do final da década de 1960, período que marcou o início da transição para uma nova lógica de acumulação do capital, à qual Harvey (2012) denominou regime de acumulação flexível. Esse regime emergiu da crise das economias de escala e caracterizou-se pelo confronto direto com a rigidez do fordismo - expressa em elementos como os contratos e as jornadas de trabalho, assim como na própria estrutura e na ação do Estado -, atuando com a finalidade de reduzir os custos com mão de obra e promover a redução do tempo de giro do capital para resolver o problema da capacidade produtiva ociosa das economias centrais.

Para resolver a crise do lado da produção, teve início um amplo processo de reestruturação produtiva, que utilizou de inovações como as dos sistemas informacionais, comunicacionais e organizacionais para fomentar a substituição do trabalho vivo pelo morto. Adequando-se a essas transformações, a regulação do trabalho assumiu uma tendência de flexibilização de sua configuração anterior, ao passo que o desemprego passou a flutuar em níveis mais elevados, os sindicatos perderam força e os ganhos salariais foram contidos ${ }^{3}$.

Para completar esse processo pelo lado da circulação, a solução da crise passava por reduzir a concorrência internacional e ampliar os mercados para os países centrais. Para tanto, era necessário deslocar os países latino-americanos de competidores industriais, para mercados consumidores, efeito que foi alcançado, entre outros expedientes, mediante a subordinação das economias periféricas no contexto da "financeirização" da economia global, por meio da qual a acumulação se dá principalmente sob os imperativos da valorização do capital pela via financeira (BRAGA, 2013).

No Brasil, esse processo ganhou força por meio da redução da liquidez internacional liderada pelos Estados Unidos na década de 1980, que levou à deterioração das contas nacionais e à consequente necessidade de obtenção de elevados saldos comerciais para financiar os déficits em transações correntes. Nessa lógica, adotou-se um processo de desregulamentação, abertura e internacionalização da economia nacional, opção que fez com que o país fícasse cada vez mais às margens da concepção de produtos, passando a especializar-se na produção de mercadorias de menor valor agregado.

$\mathrm{Na}$ esfera política, a reestruturação produtiva foi completada pela difusão do neoliberalismo, que no Brasil significou uma reconfiguração das políticas econômicas a partir da década de 1990. Com isso, ampliaram-se largamente a lógica da privatização de empresas públicas, da liberalização comercial, da valorização de capitais pela via financeira e da consequente "racionalização produtiva" diante do novo padrão de concorrência internacional:

3 Observa-se nesse contexto a ascensão do "desemprego 'estrutural' (em oposição ao 'friccional'), rápida destruição e reconstrução de habilidades, ganhos modestos (quando há) de salários reais e o retrocesso do poder sindical, [em consonância com o] crescente uso do trabalho em tempo parcial, temporário ou subcontratado" (HARVEY, 2012, p. 141-43). 
Combinando a flexibilidade produtiva garantida pela informatização com novas configurações entre o centro e a periferia da força de trabalho, as empresas brasileiras entraram, tardia porém decididamente, na era do reporting (prestação de contas aos acionistas), do track recording (histórico de desempenho) e do downsizing (enxugamento). A estrutura econômica brasileira, não sem conflitos, é verdade, foi finalmente integrada à mundialização do capital e ao neoliberalismo, transformandose em uma autêntica plataforma de valorização financeira internacional (BRAGA, 2013, p. 145).

Alguns dos efeitos mais dramáticos desse processo puderam ser observados no mercado de trabalho. Em todo o Brasil a década de 1990 representou um período de intensa precarização do mercado de trabalho, marcada pela expansão do desemprego e da informalidade, pela retração da renda e pela concentração das ocupações no setor de serviços.

Esse cenário só se alterou no começo do século XXI. A partir de 2003 a alta no ciclo de liquidez internacional deu margem para que o Brasil reduzisse as taxas de juros domésticos sem desvalorizar o câmbio. Além disso, a elevação da demanda e dos preços dos produtos primários (provocada sobretudo pelo crescimento da economia chinesa) levou à acumulação de superávits que permitiram que o governo ampliasse o gasto público, investindo em infraestrutura e implementando políticas tributárias e de crédito, o que fortaleceu o ritmo do crescimento da atividade econômica.

A conjuntura favorável e a reorientação da política econômica levaram a alterações expressivas no mercado de trabalho. Por um lado, observou-se uma consistente formalização do emprego do país ${ }^{4}$, com valorização do salário mínimo e elevação do poder de compra dos trabalhadores. Por outro lado, não houve um rompimento efetivo com o padrão exportador de especialização produtiva que se estabeleceu no país desde o processo de reestruturação produtiva, o que implicou na continuidade da penetração das formas flexíveis de organização do trabalho (OSORIO, 2012).

Com o advento da crise econômica global a partir de 2008, houve uma forte retração da demanda, ao mesmo tempo em que se "complicou ainda mais a mudança no relacionamento do Estado com os setores produtivo e financeiro, necessária para a realização dos investimentos autônomos capazes de alterar o rumo do crescimento da economia brasileira" (BALTAR, 2014, p. 108). Assim, foi-se degradando gradualmente a conjuntura favorável que sustentava os bons indicadores do mercado de trabalho brasileiro na primeira década do século XXI. Esse processo ganhou força com a consolidação da crise econômica a partir de 2015, acentuando a pressão pela flexibilização das relações trabalhistas (FILGUEIRAS; BISPO; COUTINHO, 2018).

\section{ANÁLISE DA REFORMA TRABALHISTA}

O contexto econômico mundial, sob o domínio da globalização e da ordem política neoliberal, recolocou na agenda o tema da regulação do trabalho, que perdera força no período de crescimento do emprego. Nesse contexto, vários direitos trabalhistas fundamentais que fazem parte da Organização Internacional do Trabalho (OIT) - e que foram consagrados na Declaração Universal dos Direitos Humanos das Nações Unidas - estão sendo questionados. Registrese que esses direitos são relevantes não somente para o trabalho e para a obtenção de bons resultados econômicos, mas porque eles também atuam no sentido de aprimorar os processos de democratização das nações e de garantia da justiça social. É por isso que recentemente a defesa

\footnotetext{
4 Segundo os dados da Rais (2019), o estoque de empregos formais cresceu 67,8\% no país entre 2003 e 2014.
} 
do cumprimento das normas trabalhistas internacionais voltou a ser objeto de preocupação e definição por parte das Nações Unidas ${ }^{5}$.

Partindo desse movimento geral e afirmando que o problema do desemprego decorria de anomalias existentes na Consolidação das Leis Trabalhistas (CLT), o governo Temer encaminhou ao Congresso Nacional, no dia 22 de dezembro de 2016, a primeira proposta de mudanças nas leis trabalhistas, denominada de "reforma trabalhista". Tal proposta pretendia alterar as regulamentações referentes à jornada de trabalho, à negociação entre empresários e trabalhadores, às formas de demissão, ao trabalho temporário e às férias, além de outros fatores caros às condições de trabalho e à própria dinâmica do mercado de trabalho brasileiro.

A partir de então, a proposta passou a ser defendida por vários segmentos empresariais, a maior parte deles interessada apenas em suas taxas de lucratividade. Afirmando que capital e trabalho precisam "se sentar à mesa", sobretudo em momentos de desemprego, várias lideranças empresariais passaram a defender a "flexibilização da legislação trabalhista" como instrumento de combate ao desemprego. Nesse cenário emergiram propostas que praticamente recolocariam o país ao tempo dos primórdios da colonização, destacando-se o argumento de que a atual legislação trabalhista somente protege o trabalhador e se esquece das empresas e de seu papel no mundo moderno. Além disso, acadêmicos associados ao credo neoliberal também defenderam a reforma trabalhista por considerarem que o conjunto de leis trabalhistas do país afasta os investimentos e dificulta o conhecimento dos custos de produção das empresas.

É importante registrar, ainda, que a formulação da proposta inicial de reforma foi uma tentativa do governo Temer para se legitimar perante o setor empresarial após o processo de impeachment. Em reunião, Temer com mais de uma centena de empresários de vários setores econômicos, às vésperas da "tomada do poder definitiva", assumiu o compromisso de propor mudanças na legislação trabalhista como forma de obter apoio político do empresariado brasileiro. Tal iniciativa política também teve importantes apoios, com destaque para posicionamentos de ministros do Supremo Tribunal Federal (STF) e do Tribunal Superior do Trabalho (TST).

A proposta de reforma do governo Temer foi aprovada na Câmara Federal no dia 26 de abril de 2017. Na sequência essa proposta da Câmara Federal foi encaminhada ao Senado da República. Após meses de discussões, a reforma foi aprovada em 11 de julho de 2017, com 50 votos favoráveis, 26 contrários e uma abstenção. De uma forma sucinta, serão apresentadas a seguir as mais importantes alterações do marco legal, organizadas por blocos temáticos.

Bloco I - Jornada de Trabalho

a) Jornada de trabalho: a jornada poderá ser de até 12 horas com 36 horas de descanso, dentro do limite semanal de 44 horas. Antes a jornada era limitada a 8 horas diárias, com possibilidade de duras horas extraordinárias por dia.

b) Tempo na empresa: a partir de agora as atividades no âmbito da empresa (descanso, estudo, alimentação, higiene pessoal, troca de uniforme e interação com colegas) não fazem mais parte da jornada de trabalho. Anteriormente, esses quesitos eram considerados como parte da jornada de trabalho.

c) Descanso: ao exercer uma jorna diária de 8 horas, até então o trabalhador tinha direito entre uma a duas horas (máximo) de intervalo para alimentação e repouso. A partir de agora esse intervalo deverá ser negociado, porém estabelecendo-se um tempo mínimo de 30 minutos. Caso o empregador não conceder esse intervalo

5 Na definição dos Objetivos do Desenvolvimento do Milênio, por exemplo, duas das metas estão diretamente relacionadas à necessidade de proteção dos direitos trabalhistas. 
mínimo para almoço, a indenização será de 50\% do valor da hora normal de trabalho apenas sobre o tempo não concedido e não do tempo integral do intervalo.

d) Trabalho parcial: a regra atual amplia o período de 25 para 30 horas semanais, mantendo-se a proibição de horas extras semanais. Antes não se poderia vender dias de férias proporcionais, cujo teto máximo era 18 dias. Pela nova legislação, até um terço das férias poderão ser pagas em dinheiro.

e) Transporte: a partir de agora o tempo despendido até o local de trabalho e o tempo de retorno não serão mais computados na jornada de trabalho, inclusive no caso do transporte oferecido pela empresa. Antes o tempo de deslocamento por meio de transporte oferecido pela empresa poderia ser contabilizado como parte da jornada de trabalho.

f) Novas modalidades de trabalho: $1 .^{\text {a) }}$ Trabalho Intermitente: o trabalhador poderá ser contratado por determinado tempo (prestação de serviço não contínua), devendo ficar estabelecido o período (horas, dias ou meses). O valor da hora de trabalho deverá ser especificado e não poderá ser inferior ao valor horário do salário mínimo ou à remuneração dos demais trabalhadores que exercem a mesma função. No período de inatividade, esse trabalhador poderá prestar serviços a outras empresas; 2.") Trabalho Remoto (home office): esse é um contrato de trabalho por tarefas, sendo que todos os gastos para tal, como equipamentos, energia, internet etc., deverão ser formalizados em contrato entre as partes.

g) Banco de horas: pela nova legislação, o banco de horas pode ser efetivado de forma individual e por escrito, devendo a compensação ser realizada no mesmo mês, não ficando estabelecido nenhum teto de horas diárias, como era anteriormente.

h) Gravidez e locais insalubres: pelas regras anteriores, mulheres grávidas ou lactantes não podiam trabalhar em locais insalubres e, no caso de demissão, não havia limite de tempo para avisar a empresa sobre a gravidez. A nova legislação permite que mulheres grávidas trabalhem em locais insalubres, desde que a empresa apresente atestado médico que garanta não haver risco ao bebê e à mãe. Já no caso de demissões, fixou-se um prazo de 30 dias para que as mulheres comuniquem as empresas sobre a gravidez. Após muita polêmica, essa medida veio a ser derrubada pelo STF em $2019^{6}$.

Bloco II - Formas de remuneração

a) Remuneração por produtividade: pelas regras que estavam em vigor, a remuneração por produtividade não poderia ser inferior à diária correspondente ao piso da categoria ou salário mínimo, sendo que gratificações, comissões e percentagens integravam os salários. Pela nova regra o pagamento do piso ou salário mínimo não será obrigatório na remuneração, sendo que empresas e empregados poderão negociar todas as formas de remuneração que não devem fazer parte do salário.

b) Férias: mediante negociação, a partir de agora poderão ser fracionadas em até três períodos, desde que um dos períodos seja de pelo menos 15 dias corridos. Até então as férias podiam ser fracionadas em até dois períodos, sendo que um deles não poderia ser inferior a 10 dias.

6 Cf. FOLHA DE S. PAULO. STF derruba trecho da reforma trabalhista e proíbe grávida em local insalubre, 29 mai. 2020. Disponível em: https://bit.ly/2Ce9G71. Acesso em: 30 abr. 2021. 
c) Plano de cargos e salários: a partir de agora os planos de cargos e salários poderão ser negociados entre empresas e trabalhadores sem a necessidade de homologação nem registro em contrato, podendo ser alterados a todo o momento. Antes esses planos precisavam ser homologados pelo Ministério do Trabalho.

Bloco III - Negociações Trabalhistas

a) Acordado se sobrepõe ao legislado: anteriormente à reforma, convenções e acordos coletivos podiam estabelecer condições de trabalho distintas das previstas em lei, desde que para elevar o padrão do trabalhador relativamente à legislação. A reforma estabelece que acordos e convenções definidos entre empresas e sindicatos prevalecem sobre a legislação. Por outro lado, acordos individualizados entre empresas e trabalhadores com nível superior e salário mensal igual ou duas vezes superior ao teto de benefícios do INSS (R\$ 5.839,45 em 2019) prevalecerão sobre acordos coletivos.

b) Prazo de validade das normas coletivas: as regras vigentes até a reforma estabeleciam que os acordos ou convenções coletivas só podiam ser modificados por novas negociações, uma vez que passada a validade as regras permaneciam válidas até nova negociação coletiva. Pela nova legislação, empresas poderão manter ou não as cláusulas previstas após o final da vigência da negociação coletiva, uma vez que o negociado não precisa mais ser incorporado ao contrato de trabalho.

c) Rescisão Contratual: pela nova legislação, a rescisão contratual não precisará mais ser homologada pelos sindicatos, podendo ser realizada nas empresas na presença de advogados destas e do empregado.

d) Demissão: este quesito foi totalmente alterado pela nova legislação, uma vez que o contrato de trabalho poderá ser extinto de comum acordo entre as partes, caso em que o empregador pagará somente $50 \%$ do aviso prévio e metade da multa de $40 \%$ sobre o saldo do FGTS, enquanto o trabalhador não terá direito ao segurodesemprego.

e) Multas: pelas regras anteriores, as empresas estavam sujeitas ao pagamento de um salário mínimo por empregado não registrado, acrescido de igual valor em cada reincidência. A nova legislação estabeleceu que a multa para cada empregado não registrado será de $\mathrm{R} \$ 3.000,00$, caindo para $\mathrm{R} \$ 800,00$ para micro e pequenas empresas.

f) Ações na justiça: pelas regras anteriores, os honorários das perícias eram pagos pela União e não recaía nenhum custo sobre o trabalhador que entrava com a ação. Pelas novas regras, caso o trabalhador que ingressou com a ação perder, terá de arcar com os custos do processo. Além disso, quem perder a causa terá de pagar entre $5 \% \mathrm{e}$ $15 \%$ do valor da sentença como honorários de sucumbência, que são devidos aos advogados da parte vencedora. Também ficou estabelecida multa de $1 \%$ a $10 \%$ do valor da causa, mais indenização para a parte contrária, a todos aqueles que agirem de má-fé. Finalmente, o empregado que assinar rescisão contratual estará impedido de questioná-la posteriormente na Justiça do Trabalho.

g) Danos morais: anteriormente eram os juízes que estipulavam o valor das ações sobre danos morais. A nova legislação estipulou um teto aos valores pleiteados para vários casos, sendo que ofensas graves cometidas pelos empregadores terão um teto de, no máximo, 50 vezes ao último salário do reivindicante. 
Bloco IV - Representação Sindical

a) Representação sindical: a Constituição assegura a representação de um delegado sindical nas empresas com mais de 200 empregados, o qual tinha todos os direitos trabalhistas e estabilidade no emprego por um período de dois anos. Pelas novas regras, os trabalhadores dessas mesmas empresas poderão escolher três funcionários para representá-los nas negociações com os empregadores, não precisando ser sindicalizados.

b) Contribuição Sindical: na lógica da mudança anterior, a nova lei tornou a contribuição sindical opcional. Anteriormente a contribuição era obrigatória, sendo equivalente a um dia de salário do trabalhador.

De uma maneira geral, percebe-se que o Estado - enquanto aparato institucionallegal mediador dos conflitos entre capital e trabalho - perdeu sua importância no processo de reforma. Além disso, busca-se recompor o nível de rendimentos da classe empresarial em detrimento da classe trabalhadora, mobilizando diversos instrumentos poderosos: por um lado, foi enfraquecido o papel dos sindicatos e limitado o acesso à Justiça do Trabalho e, por outro, flexibilizam-se as regras relativas à jornada de trabalho e às condições de execução da atividade laboral. Ao mesmo tempo, a legalização do trabalho intermitente permite que o empregador tenha a seu dispor determinada força de trabalho em tempo integral, porém remunerando-a apenas pelas horas efetivamente trabalhadas.

Todos esses aspectos poderão levar a um processo de pauperização de importantes segmentos da classe trabalhadora que, em um cenário de desemprego elevado, se vê submetida a essas novas relações trabalhistas. Assim, e de forma bastante resumida, podemos sintetizar a reforma trabalhista da seguinte maneira: o seu eixo central permite que, por diferentes vias, se possam reduzir os "custos com trabalho" em detrimento da restrição ou da eliminação de direitos dos trabalhadores, até mesmo aqueles garantidos constitucionalmente. Com isso, a antiga CLT se tornou, na prática, um arcabouço legal de proteção empresarial, a serviço dos empregadores.

\section{PANORAMA RECENTE DO MERCADO DE TRABALHO CATARINENSE}

Segundo os defensores da reforma trabalhista, eliminar a "rigidez" da legislação do trabalho no Brasil seria benéfico à economia e ao mercado de trabalho, pois levaria à redução dos custos do trabalho e, por consequência, aumentaria a geração de empregos ${ }^{7}$. Esse argumento, compatível com a teoria econômica neoclássica, associa a geração de empregos às próprias variáveis do mercado de trabalho, não ao nível de investimento da economia. Cabe analisar, portanto, se esses supostos impactos se verificaram no mercado de trabalho catarinense.

Apesar de se manter como o estado com o menor índice de desemprego do país, o mercado de trabalho de Santa Catarina também foi diretamente afetado pela dinâmica econômica nacional recente. Com base nos dados trimestrais da PNAD Contínua ${ }^{8}$, a Tabela 1 revela que a

\footnotetext{
7 Nas palavras do relator do projeto que tramitou no Congresso: "Em nosso país, além do excesso de normas trabalhistas, elas são muito rígidas. E essa rigidez, por sua vez, provoca um alto grau de insegurança jurídica na contratação do trabalhador, fazendo com que, primeiro, o empregador tenha receio de contratar a mão de obra e, depois, que investimentos importantíssimos para o crescimento do País sejam direcionados a outros países" (MARINHO, 2016, p. 21).

8 Sobre os principais aspectos metodológicos da PNAD Contínua e sua aplicação na análise da conjuntura recente do mercado de trabalho brasileiro, ver Mattei e Heinen (2019).
} 
população em idade ativa (14 ou mais anos de idade) em Santa Catarina cresceu à taxa anual de $1,5 \%$ entre 2014 e 2018 , enquanto a força de trabalho cresceu $2,1 \%$ ao ano no mesmo período. Com isso, a taxa de participação na força de trabalho saiu dos $63,3 \%$ em que se encontrava em 2014, para 64,8\% em 2018, com destaque para o crescimento da procura por trabalho em 2017.

\section{TABELA 1 - PESSOAS DE 14 ANOS OU MAIS DE IDADE, POR CONDIÇÃO EM RELAÇÃO À FORÇA DE TRABALHO E CONDIÇÃO DE OCUPAÇÃO, SANTA CATARINA (MIL PESSOAS, 2014-2018, 3. ${ }^{\circ}$ TRIMESTRE DE CADA ANO)}

\begin{tabular}{lcccccc}
\hline & $\mathbf{2 0 1 4}$ & $\mathbf{2 0 1 5}$ & $\mathbf{2 0 1 6}$ & $\mathbf{2 0 1 7}$ & $\mathbf{2 0 1 8}$ & $\begin{array}{c}\text { Taxa } \\
\text { a.a. } \\
\mathbf{( \% )}\end{array}$ \\
\hline Pessoas de 14 ou mais anos de idade & 5.540 & 5.635 & 5.715 & 5.802 & 5.885 & 1,5 \\
Força de trabalho & 3.508 & 3.616 & 3.645 & 3.802 & 3.815 & 2,1 \\
/ Ocupada & 3.407 & 3.458 & 3.413 & 3.545 & 3.580 & 1,2 \\
/ Desocupada & 102 & 157 & 232 & 256 & 236 & 23,3 \\
Fora da força de trabalho & 2.032 & 2.019 & 2.070 & 2.000 & 2.070 & 0,5 \\
$\begin{array}{l}\text { Taxa de participação na força de } \\
\text { trabalho (\%) }\end{array}$ & 63,3 & 64,2 & 63,8 & 65,5 & 64,8 & \\
\hline
\end{tabular}

Fonte: PNADC/T (2019); Elaboração própria.

Tal qual ocorreu no conjunto do país, também em Santa Catarina a crise econômica levou a uma drástica ascensão da desocupação a partir de 2015. Com a acentuada queda da atividade econômica no estado ${ }^{9}$, o número de desocupados aumentou 2,3 vezes em apenas dois anos, subindo de 102 mil pessoas, em 2014, para 232 mil pessoas, em 2016. Já em 2017, a retomada de alguns setores de atividade econômica promoveu um aumento da população ocupada, no entanto, em um ritmo inferior ao incremento da força de trabalho. Com isso, a taxa de desocupação estadual saltou de 2,9\%, em 2014, para 6,7\%, em 2017 (Tabela 2).

Registre-se que foi em meio a esse cenário que a reforma trabalhista foi aprovada. Apesar disso, em 2018 não houve a grande geração de empregos prometida pelos defensores da reforma. Na verdade, o nível de ocupação seguiu ancorado no desempenho econômico geral do estado, de modo que o crescimento da população ocupada em 2018 foi inferior, inclusive, ao registrado em $2017^{10}$. Apesar de a população desocupada ter caído para 236 mil pessoas, a taxa de desocupação permaneceu em $6,2 \%$, o que pode ser considerado um nível muito elevado para os patamares estaduais.

O PIB real de Santa Catarina sofreu queda de 4,2\% em 2015 e de 2\% em 2016 (SEF/SC, 2019).

$10 \mathrm{O}$ ano de 2017 foi marcado pela retomada de importantes setores de atividade econômica do estado, o que levou a um crescimento de 4\% no PIB catarinense. Para 2018, estima-se um crescimento um pouco abaixo desse nível, na casa dos 3,6\% (SEF/SC, 2019). 


\section{TABELA 2 - MEDIDAS DE SUBUTILIZAÇÃO DA FORÇA DE TRABALHO, SANTA CATARINA (MIL PESSOAS, 2014-2018, 3. ${ }^{\circ}$ TRIMESTRE DE CADA ANO)}

\begin{tabular}{ccccccccc|}
\hline & \multicolumn{2}{c}{ Desocupada } & \multicolumn{2}{c}{$\begin{array}{c}\text { Subocupada por } \\
\text { insuf. de horas trab. }\end{array}$} & \multicolumn{2}{c|}{$\begin{array}{c}\text { Força de trabalho } \\
\text { potencial }\end{array}$} & $\begin{array}{c}\text { Força de trabalho } \\
\text { subutilizada }\end{array}$ \\
\hline & Abs. & Rel. $(\%)$ & $A b s$. & Rel. $(\%)$ & $A b s$. & Rel. $(\%)$ & $A b s$. & Rel. (\%) \\
2014 & 102 & 2,9 & 46 & 1,3 & 34 & 1 & 182 & 5,1 \\
2015 & 157 & 4,3 & 68 & 1,9 & 39 & 1,1 & 264 & 7,5 \\
2016 & 232 & 6,4 & 62 & 1,8 & 67 & 1,9 & 361 & 10,2 \\
2017 & 256 & 6,7 & 81 & 2,3 & 86 & 2,4 & 423 & 11,9 \\
2018 & 236 & 6,2 & 103 & 2,9 & 98 & 2,8 & 437 & 12,3 \\
Taxa a.a. (\%) & $\mathbf{2 3 , 3}$ & & $\mathbf{2 2 , 3}$ & & $\mathbf{3 0 , 3}$ & & $\mathbf{2 4 , 5}$ & \\
\hline
\end{tabular}

Fonte: PNADC/T (2019); Elaboração dos autores.

Nota: Para a taxa de desocupação, o denominador é a força de trabalho. Nos demais casos, o denominador é a força de trabalho ampliada (força de trabalho + força de trabalho potencial).

Da mesma forma, a melhoria no nível de emprego em Santa Catarina tampouco pôde ser observada nas demais medidas de subutilização da força de trabalho apresentadas na Tabela 2. A primeira dessas medidas diz respeito aos subocupados por insuficiência de horas trabalhadas, que representam um contingente de trabalhadores que procura expandir sua jornada de trabalho vigente, geralmente por considerar seus rendimentos atuais insuficientes. Essa categoria apresentou um crescimento médio de $22,3 \%$ ao ano no conjunto da série, chegando a abranger 103 mil pessoas, ou seja, $2,9 \%$ da força de trabalho ampliada existente em 2018 . O crescimento acelerado dessa categoria indica que grande parte dos postos de trabalho criados no estado nos últimos anos foi, na verdade, de subempregos ${ }^{11}$.

A segunda medida refere-se à força de trabalho potencial, que é composta pelas pessoas que realizaram busca efetiva por trabalho, mas que não estavam disponíveis para trabalhar naquele momento; além dos desalentados, ou seja, as pessoas que estavam disponíveis para trabalhar, mas não realizaram busca efetiva por trabalho. Essa categoria apresentou um crescimento anual médio de $30,3 \%$ ao longo da série, ampliando sua participação de $1 \%$ para $2,8 \%$ entre 2014 e 2018.

Agregando-se essas duas categorias aos desocupados, chega-se à força de trabalho subutilizada. Em 2014, a taxa composta de subutilização da força de trabalho do estado era de apenas 5,1\%. Desde então, a população subutilizada cresceu em média $24,5 \%$ ao ano. Com isso, a taxa de subutilização chegou a 12,3\% em 2018, abrangendo um total de 437 mil pessoas, o maior nível da série histórica da PNAD Contínua. Esse resultado se deve a um crescimento contínuo da subutilização ao longo de todo o período analisado, a despeito da incipiente retomada do nível de emprego observada a partir de 2017.

Além disso, é importante recordar que a reforma trabalhista foi aprovada sob o pretexto de combater a informalidade no emprego, a qual, segundo seus defensores, estaria

\footnotetext{
${ }^{11}$ De acordo com os dados da PNADC/T (2019), o crescimento no número de subocupados em 2018 foi equivalente a cerca de um terço da variação da população ocupada registrada no mesmo ano.
} 
sendo fomentada pelo excesso de legislação trabalhista exigida para contratações formais ${ }^{12}$. Essa afirmação pode ser analisada com base na Tabela 3, que dá indicativos importantes sobre a evolução recente da informalidade no mercado de trabalho catarinense.

\section{TABELA 3 - FORÇA DE TRABALHO OCUPADA POR POSIÇÃO NA OCUPAÇÃO E CATEGORIA NO EMPREGO EM SANTA CATARINA (MIL PESSOAS, 2014-2028, 3. TRIMESTRE DE CADA ANO)}

\begin{tabular}{|c|c|c|c|c|c|c|c|}
\hline & & & & & & & Taxa a.a. (\%) \\
\hline \multirow{2}{*}{$\begin{array}{l}\text { Empregado (exclusive doméstico) } \\
\text { com carteira de trabalho assinada }\end{array}$} & Abs. & 1818 & 1775 & 1728 & 1774 & 1795 & $-0,3$ \\
\hline & $\begin{array}{l}\text { Rel. } \\
(\%)\end{array}$ & 53,4 & 51,3 & 50,7 & 50,1 & 50,2 & - \\
\hline \multirow{2}{*}{$\begin{array}{l}\text { Empregado (exclusive doméstico) } \\
\text { sem carteira de trabalho assinada }\end{array}$} & Abs. & 236 & 262 & 258 & 291 & 297 & 5,9 \\
\hline & $\begin{array}{l}\text { Rel. } \\
(\%)\end{array}$ & 6,9 & 7,6 & 7,5 & 8,3 & 8,3 & - \\
\hline \multirow[b]{2}{*}{ Trabalhador doméstico } & Abs. & 131 & 126 & 145 & 163 & 156 & 4,5 \\
\hline & $\begin{array}{l}\text { Rel. } \\
(\%)\end{array}$ & 3,8 & 3,6 & 4,3 & 4,6 & 4,4 & - \\
\hline \multirow{2}{*}{$\begin{array}{l}\text { Funcionário público estatutário ou } \\
\text { militar }\end{array}$} & Abs. & 243 & 271 & 253 & 258 & 266 & 2,3 \\
\hline & $\begin{array}{l}\text { Rel. } \\
(\%)\end{array}$ & 7,1 & 7,8 & 7,4 & 7,3 & 7,4 & - \\
\hline \multirow[b]{2}{*}{ Empregador } & Abs. & 171 & 184 & 198 & 203 & 196 & 3,5 \\
\hline & $\begin{array}{l}\text { Rel. } \\
(\%)\end{array}$ & 5 & 5,3 & 5,8 & 5,7 & 5,5 & - \\
\hline \multirow[b]{2}{*}{ Conta própria } & Abs. & 706 & 734 & 754 & 795 & 790 & 2,9 \\
\hline & $\begin{array}{l}\text { Rel. } \\
(\%)\end{array}$ & 20,7 & 21,2 & 22,1 & 22,4 & 22,1 & - \\
\hline \multirow[b]{2}{*}{ Trabalhador familiar auxiliar } & Abs. & 101 & 106 & 76 & 60 & 79 & $-6,0$ \\
\hline & $\begin{array}{l}\text { Rel. } \\
(\%)\end{array}$ & 3 & 3,1 & 2,2 & 1,7 & 2,2 & - \\
\hline Total & Abs. & 3407 & 3458 & 3413 & 3545 & 3580 & 1,2 \\
\hline
\end{tabular}

Fonte: PNADC/T (2020); Elaboração dos autores.

Inicialmente, observa-se que a maioria das ocupações criadas entre 2014 e 2018 foi de empregados sem carteira de trabalho assinada e de trabalhadores por conta própria, que cresceram $5,9 \%$ e $2,9 \%$ ao ano, respectivamente. Além desses grupos, os trabalhadores domésticos $(4,5 \%$ ao ano), os empregadores (3,5\% ao ano) e os funcionários públicos estatuários ou militares $(2,3 \%$ ao ano) também acumularam saldos positivos ao longo da série.

Já a categoria dos empregados com carteira de trabalho assinada decresceu em média $0,3 \%$ ao ano no conjunto do período. Com isso, sua participação no agregado das ocupações caiu 3,2 pontos percentuais entre 2014 e 2018 , chegando a 50,2\% neste último ano. Esse resultado ajuda a explicar o crescimento das ocupações sem registro, que surge como consequência da baixa oferta de empregos formais no estado. Esse processo pode ser melhor visualizado a partir

\footnotetext{
12 “A preocupação desta Casa, ao examinar a proposição, não pode se restringir ao universo dos empregados formais, é preciso pensar naqueles que estão relegados à informalidade, ao subemprego, muitas vezes por que a sua realidade de vida não se encaixa na forma rígida que é a atual CLT. A legislação trabalhista brasileira vigente hoje é um instrumento de exclusão, prefere deixar as pessoas à margem da modernidade e da proteção legal do que permitir contratações atendendo as vontades e as realidades das pessoas" (MARINHO, 2016, p. 19).
} 
da Figura 1, que apresenta a contribuição das ocupações formais e informais no crescimento da população ocupada com renda do trabalho em Santa Catarina.

\section{FIGURA 1 - CONTRIBUIÇÃO DE OCUPAÇÕES FORMAIS E INFORMAIS PARA O CRESCIMENTO DA POPULAÇÃO OCUPADA COM RENDIMENTOS DO TRABALHO EM SANTA CATARINA (2014-2018, VARIAÇÃO COM RELAÇÃO AO MESMO TRIMESTRE DO ANO ANTERIOR, EM \%)}

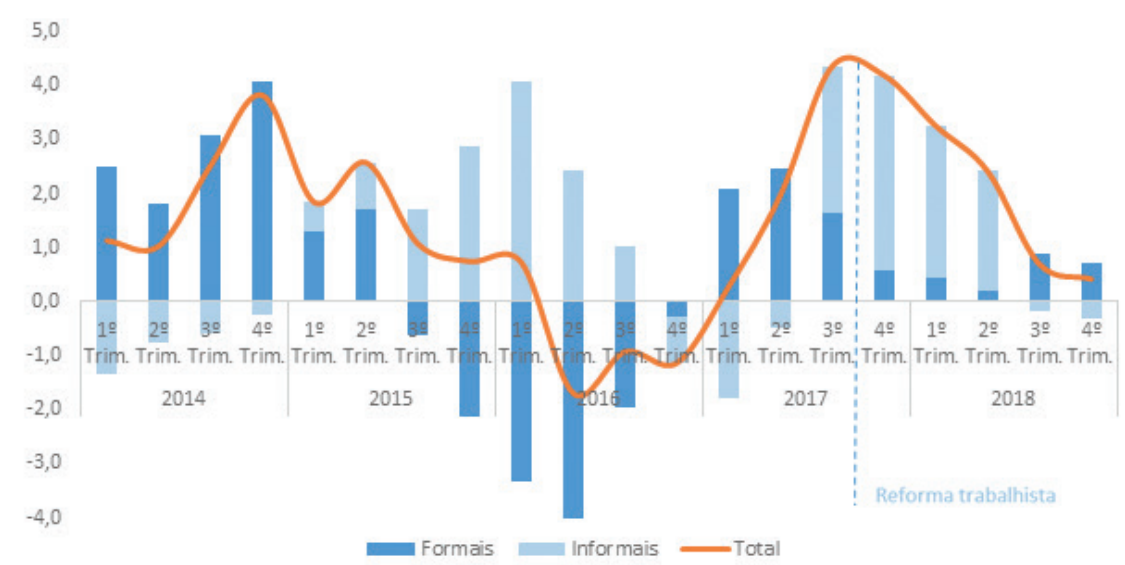

Fonte: PNADC/T (2019); Elaboração dos autores.

Nota 1: Formais $=$ empregados (inclusive domésticos) com carteira de trabalho assinada + funcionários públicos estatuários e militares; Informais = empregados sem carteira + conta própria.

Nota 2: A contribuição de cada categoria é definida como o produto entre sua taxa de crescimento em relação ao mesmo trimestre do ano anterior e a sua participação na população ocupada com renda do trabalho.

Após o período de intensa informalização do mercado de trabalho iniciado em 2015, nota-se que o grau de formalização do emprego no estado voltou a apresentar uma incipiente melhora a partir de 2017, contrariamente ao comportamento observado no mercado de trabalho do país, cuja informalidade seguiu crescendo até 2018 (MATTEI; HEINEN, 2019).

No mesmo sentido do que se observou quanto ao nível de ocupação, esse comportamento distinto da formalização do emprego em âmbito estadual também está associado à estrutura produtiva e ao nível de investimento da economia, sem guardar qualquer correlação significativa com a introdução da reforma trabalhista (BIAVASCHI et al, 2018). Em razão disso, é importante analisar a evolução das ocupações nos distintos setores de atividade econômica do estado.

Com base nas informações da Tabela 4, percebe-se que o aumento do desemprego e da informalidade derivou especialmente da contração do setor manufatureiro, atividade que ainda se mantém muito expressiva no estado. Com taxa de crescimento de $-0,7 \%$ ao ano, a participação da indústria geral no agregado das ocupações estaduais caiu de $25,9 \%$, em 2014, para $24 \%$, em 2018. Em grande medida, essa retração se concentrou no biênio 2015-2016, período no qual o setor fechou 61 mil postos de trabalho. Após abrupta queda, alguns ramos da indústria entraram em fase de recuperação, de modo que a produção industrial catarinense assumiu um ritmo de crescimento superior à média nacional, destacadamente em 2017 ${ }^{13}$. Com isso, também houve

\footnotetext{
13 A produção física da indústria catarinense registrou crescimento de 4,5\% em 2017, enquanto a média nacional ficou em 2,5\% (PIM-PF, 2019).
} 
uma retomada das contratações no setor, que, por serem majoritariamente formais, ajudaram a conter o avanço da informalidade no estado (MATTEI; HEINEN; FRONZA, 2019).

\section{TABELA 4 - FORÇA DE TRABALHO OCUPADA POR GRUPAMENTO DE ATIVIDADE ECONÔMICA NO TRABALHO PRINCIPAL, SANTA CATARINA (MIL PESSOAS, 2014- 2018, 3. ${ }^{\circ}$ TRIMESTRE DE CADA ANO)}

\begin{tabular}{|c|c|c|c|c|c|c|c|}
\hline \multirow{2}{*}{$\begin{array}{l}\text { Agricultura, pecuária, produção flores- } \\
\text { tal, pesca e aquicultura }\end{array}$} & $A b s$. & 325 & 357 & 374 & 347 & 334 & $\mathbf{0 , 7}$ \\
\hline & $\begin{array}{l}\text { Rel. } \\
(\%)\end{array}$ & 9,5 & 10,3 & 11 & 9,8 & 9,3 & - \\
\hline \multirow[b]{2}{*}{ Indústria geral } & $A b s$. & 883 & 841 & 822 & 867 & 858 & $-0,7$ \\
\hline & $\begin{array}{l}\text { Rel. } \\
(\%)\end{array}$ & 25,9 & 24,3 & 24,1 & 24,5 & 24 & - \\
\hline \multirow[b]{2}{*}{ Construção } & $A b s$ & 221 & 242 & 251 & 242 & 248 & 2,9 \\
\hline & $\begin{array}{l}\text { Rel. } \\
(\%)\end{array}$ & 6,5 & 7 & 7,3 & 6,8 & 6,9 & - \\
\hline \multirow{2}{*}{$\begin{array}{l}\text { Comércio, reparação de veículos auto- } \\
\text { motores e motocicletas }\end{array}$} & $A b s$ & 631 & 631 & 604 & 612 & 624 & $-0,3$ \\
\hline & $\begin{array}{l}\text { Rel. } \\
(\%)\end{array}$ & 18,5 & 18,2 & 17,7 & 17,2 & 17,4 & - \\
\hline \multirow[b]{2}{*}{ Transporte, armazenagem e correio } & Abs. & 145 & 149 & 148 & 170 & 156 & 1,8 \\
\hline & $\begin{array}{l}\text { Rel. } \\
(\%)\end{array}$ & 4,3 & 4,3 & 4,3 & 4,8 & 4,4 & - \\
\hline \multirow[b]{2}{*}{ Alojamento e alimentação } & Abs. & 116 & 132 & 123 & 152 & 153 & 7,2 \\
\hline & $\begin{array}{l}\text { Rel. } \\
(\%)\end{array}$ & 3,4 & 3,8 & 3,6 & 4,3 & 4,3 & - \\
\hline \multirow{2}{*}{$\begin{array}{l}\text { Informação, comunicação e atividades } \\
\text { financeiras, imobiliárias, profissionais e } \\
\text { administrativas }\end{array}$} & Abs. & 364 & 364 & 325 & 335 & 365 & 0,1 \\
\hline & $\begin{array}{l}\text { Rel. } \\
(\%)\end{array}$ & 10,7 & 10,5 & 9,5 & 9,4 & 10,2 & - \\
\hline \multirow{2}{*}{$\begin{array}{l}\text { Administração pública, defesa, seguri- } \\
\text { dade social, educação, saúde humana e } \\
\text { serviços sociais }\end{array}$} & $A b s$ & 468 & 492 & 487 & 511 & 538 & 3,5 \\
\hline & $\begin{array}{l}\text { Rel. } \\
(\%)\end{array}$ & 13,7 & 14,2 & 14,3 & 14,4 & 15 & - \\
\hline \multirow[b]{2}{*}{ Outro serviço } & $A b s$ & 122 & 125 & 132 & 144 & 146 & 4,6 \\
\hline & $\begin{array}{l}\text { Rel. } \\
(\%)\end{array}$ & 3,6 & 3,6 & 3,9 & 4 & 4,1 & - \\
\hline \multirow[b]{2}{*}{ Serviço doméstico } & Abs. & 131 & 126 & 147 & 165 & 156 & 4,5 \\
\hline & $\begin{array}{l}\text { Rel. } \\
(\%)\end{array}$ & 3,8 & 3,6 & 4,3 & 4,6 & 4,4 & - \\
\hline Total & $A b s$. & 3407 & 3458 & 3413 & 3545 & 3580 & 1,2 \\
\hline
\end{tabular}

Fonte: PNADC/T (2019); Elaboração dos autores.

O grupamento do comércio, reparação de veículos automotores e motocicletas também apresentou saldo negativo no período, com variação de $-0,3 \%$ ao ano. Após forte contração em 2015 e em 2016, esse setor entrou em uma fase de significativa recuperação nos dois últimos anos da série, o que lhe permitiu seguir concentrando a segunda maior parcela da força de trabalho ocupada do estado, ou seja, 17,4\% de seu total em 2018.

Mesmo com saldos positivos, ficaram ainda abaixo da taxa de crescimento da força de trabalho agregada os grupamentos de informação, comunicação e atividades financeiras, 
imobiliárias, profissionais e administrativas $(0,1 \%$ ao ano); agricultura, pecuária, produção florestal, pesca e aquicultura $(0,7 \%$ ao ano); e transporte, armazenagem e correio $(1,8 \%$ ao ano). Quanto à participação desses setores no agregado, vale registrar particularmente o forte crescimento que o primeiro deles auferiu em 2018, quando retomou a ocupação de $10,2 \%$ dos trabalhadores catarinenses, contribuindo para o crescimento do emprego formal ${ }^{14}$.

Apesar do desempenho mais discreto dos grupos supracitados, e do crescimento levemente acima da média do grupamento da construção (2,9\% ao ano), via de regra as ocupações continuam se deslocando para o setor de serviços em Santa Catarina. No conjunto do período analisado, as maiores taxas anuais de crescimento foram registradas nos grupamentos de alojamento e alimentação (7,2\%); outro serviço (4,6\%); serviço doméstico (4,5\%); e administração pública, defesa, seguridade social, educação, saúde humana e serviços sociais $(3,5 \%)$.

\section{ANÁLISE DOS IMPACTOS ESPECÍFICOS DA REFORMA TRABALHISTA SOBRE O MERCADO DE TRABALHO CATARINENSE}

As informações analisadas na seção anterior permitem afirmar que as principais promessas dos defensores da reforma trabalhista não se concretizaram no mercado de trabalho catarinense. Esses resultados estão de acordo com a análise realizada na primeira seção do artigo, que localizou essa reforma em um contexto histórico de flexibilização e de precarização das relações de trabalho. Neste sentido, é importante enfrentar o desafio de tentar dimensionar os impactos da nova legislação no estado, sabendo de antemão das dificuldades que tal intuito encontrará.

A principal dessas dificuldades é a de tentar mensurar quantitativamente as diversas e profundas mudanças qualitativas decorrentes da reforma. Além disso, há um segundo agravante relativo às bases de dados oficiais, uma vez que poucas delas incorporaram em seus registros os novos atributos formais definidos pela reforma, especialmente aqueles referentes aos contratos de trabalho. Até o momento, apenas o extinto Ministério do Trabalho havia avançado nesse sentido, ao incorporar novos indicadores em suas bases administrativas (Rais e Caged) ao final de 2017.

Há dois pontos elencados na segunda seção deste artigo que passaram a aparecer como indicadores nos registros do Ministério do Trabalho: as modalidades de trabalho intermitente e parcial. A despeito de comporem uma pequena parte das mudanças contidas na nova legislação trabalhista, essas duas modalidades já permitem captar algumas expressões da reforma no mercado de trabalho catarinense, oferecendo indicativos da dispersão e da dimensão de seus impactos.

Para dar início a essa análise, a Tabela 5 apresenta o estoque de vínculos formais de trabalho em Santa Catarina nos anos de 2017 e de 2018, bem como a parcela deles que se encontrava em regimes de trabalho parcial ou intermitente. Esses dados se baseiam nos registros da Relação Anual de Informações Sociais (Rais), de modo que indicam a quantidade de vínculos ativos em 31 de dezembro de cada ano.

Ao final de 2017, ou seja, poucos meses após a reforma trabalhista ter entrado em vigor, Santa Catarina contava com 6.735 vínculos formais de trabalho em regime parcial e 295

\footnotetext{
14 Da mesma forma que a indústria, o setor de informação, comunicação e atividades financeiras, imobiliárias, profissionais e administrativas tem um dos maiores graus de formalização do estado, sendo um dos principais determinantes do comportamento do mercado formal de trabalho.
} 
em regime intermitente. Com isso, a participação do trabalho intermitente no agregado era de $0,31 \%$, o que se deve basicamente aos vínculos que já se encontravam ativos antes da reforma trabalhista, que não introduziu essa modalidade de trabalho, apenas a ampliou ${ }^{15}$. De forma distinta, a participação quase nula dos vínculos intermitentes $(0,01 \%)$ se deve ao fato dessa modalidade ter sido introduzida pela reforma.

\section{TABELA 5 - ESTOQUE DE VÍNCULOS FORMAIS DE TRABALHO E PARTICIPAÇÃO DAS MODALIDADES DE TRABALHO PARCIAIS E INTERMITENTES EM SANTA CATARINA (2017 E 2018, VÍNCULOS ATIVOS EM 31 DE DEZEMBRO DE CADA ANO)}

\begin{tabular}{lcccccc}
\hline & \multicolumn{2}{c}{ Total } & \multicolumn{2}{c}{ Trab. Parcial } & \multicolumn{2}{c}{ Trab. Intermitente } \\
& Abs. & Rel. (\%) & Abs. & Rel. (\%) & Abs. & Rel. (\%) \\
\hline 2017 & 2.205 .443 & 100 & 6.735 & 0,31 & 295 & 0,01 \\
2018 & 2.252 .440 & 100 & 12.625 & 0,56 & 2.478 & 0,11 \\
Var. & 46.997 & - & 5.890 & 0,26 & 2.181 & 0,1 \\
\hline
\end{tabular}

Fonte: RAIS (2019). Elaboração dos autores.

Já ao final de 2018, o número de vínculos parciais no estado havia saltado para 12.525 e os intermitentes para 2.478. Em termos relativos, esses montantes passaram a representar $0,56 \%$ e $0,11 \%$ do agregado estadual, respectivamente. Isso indica que ambas as modalidades apresentaram crescimento relativo no período, com destaque para o trabalho parcial, cuja participação aumentou 0,26 pontos percentuais, superando inclusive a média nacional ${ }^{16}$.

Analisando esses dados, nota-se que as participações registradas ainda foram relativamente baixas no estado, a exemplo do que ocorre no conjunto do país. De acordo com Krein et al. (2018), para compreender esse fenômeno é preciso ter claro que a flexibilidade no desligamento é uma característica estrutural do mercado de trabalho brasileiro, razão pela qual as formas atípicas de contratação - a exemplo das contratações intermitentes e parciais - não são imprescindíveis às empresas, que já contam com grande liberdade para demitir trabalhadores mesmo com contratos por tempo indeterminado. Ademais, deve-se considerar que a mudança na legislação ainda é recente, de modo que o período analisado se enquadra em uma fase de assimilação das novas modalidades de trabalho por parte dos contratantes.

Tendo em vista esses dois fatores, o crescimento das contratações parciais e intermitentes observado em Santa Catarina pode ser considerado expressivo. Nesse sentido, o fato das contratações parciais e intermitentes já terem representado, respectivamente, $12,5 \%$ e 4,6\% do total dos empregos formais gerados no estado em 2018, torna-se efetivamente preocupante, por representar uma tendência de ampliação do número de trabalhadores que se encontram subempregados.

\footnotetext{
15 Os dados do Cadastro Geral de Empregados e Desempregados - Caged (2019), revelam que o número de contratos em regime parcial firmados nos últimos meses de 2017 foi quase nulo.

16 A participação do trabalho parcial no estoque de vínculos formais de trabalho do país foi de $0,38 \%$ em 2018 . No mesmo ano, a participação do trabalho intermitente ficou em $0,13 \%$ no conjunto do país, o que representa um percentual mais próximo ao registrado em Santa Catarina (RAIS, 2019).
} 
Muito embora as inconsistências contidas nos dados da Rais referentes às jornadas e à remuneração dos contratos intermitentes ${ }^{17}$ dificultem esta análise, as informações relativas ao trabalho parcial podem dar indicativos importantes sobre a qualidade desses vínculos. De acordo com os dados da Tabela 6, a jornada de trabalho média de um trabalhador parcial em Santa Catarina era de 19,5 horas em 2018, enquanto a dos demais trabalhadores era de 41,1 horas. Em razão disso, a remuneração mensal média dos trabalhos parciais (R\$1.421) também foi bastante inferior à dos demais vínculos ( $\mathrm{R} \$ 2.670)$.

Ainda que o valor do salário/hora recebido pelos trabalhadores parciais $(\mathrm{R} \$ 16,4)$ possa ser um pouco superior à média dos demais empregados $(\mathrm{R} \$ 14,6)$, a tendência é que a quantidade de horas efetivamente trabalhadas por eles faça com que seus rendimentos totais em um posto de trabalho não sejam suficientes para o seu sustento. Essa realidade é evidenciada pelo fato de que $53,4 \%$ dos vínculos parciais do estado tinham jornadas de até 20 horas semanais, e 45,2\% não recebiam mais que um salário mínimo em 2018. Em contraste, nota-se que essas parcelas foram de $4,1 \%$ e $3,4 \%$, respectivamente, para os trabalhadores não parciais.

\section{TABELA 6 - COMPARAÇÃO ENTRE JORNADAS DE TRABALHO E RENDIMENTOS DE TRABALHADORES PARCIAIS E NÃO PARCIAIS EM SANTA CATARINA (VÍNCULOS ATIVOS EM 31 DEZ. 2018)}

\begin{tabular}{lcc}
\hline & Trab. Parcial & Não parcial \\
\hline Jornada de trabalho média (horas) & 19,5 & 41,1 \\
Remuneração média (R\$) & 1.421 & 2.670 \\
Remuneração/hora média (R \$hora) & 16,4 & 14,6 \\
Part. Jornadas de até 20h (\%) & 53,4 & 4,1 \\
Part. Remunerações de até 1 SM (\%) & 45,2 & 3,4 \\
\hline
\end{tabular}

Fonte: RAIS (2019); Elaboração dos autores.

Nota: Jornadas de trabalho obtidas com base na variável "Quantidade de horas contratadas".

Em linhas gerais, é provável que o mesmo cenário observado para os trabalhadores parciais apareça de forma ainda mais extremada no caso dos trabalhadores intermitentes, para quem a instabilidade tende a ser ainda maior ${ }^{18}$. Nesse sentido, há um impulso à precarização das relações trabalhistas, uma vez que ambas as modalidades estão associadas à intensificação do trabalho, à restrição do acesso aos direitos trabalhistas, à insegurança no emprego e à redução das contribuições previdenciárias (CESIT, 2017).

Para dar uma noção mais concreta dos casos em que cada uma dessas modalidades de trabalho está sendo utilizada no estado, a Tabela 7 apresenta os subgrupos de ocupação com maior incidência de contratos parciais nos empregos formais gerados em Santa Catarina em 2018, enquanto a Tabela 8 apresenta a mesma relação para os contratos intermitentes.

\footnotetext{
17 O caráter "zero hour contract" da prestação de trabalhos intermitentes gera problemas no modo de declaração dessas informações. Conforme os registros da Rais (2019), a jornada de trabalho média dos intermitentes ficou próxima de 1 hora em 2018. Isso pode indicar que grande parte dos empregadores esteja declarando a quantidade de horas contratadas como zero. Além disso, há indícios de que os empregadores estejam declarando as remunerações com base no salário/hora de cada contrato, o que torna os dados inconsistentes.

18 Adaptando o método de cálculo do DIEESE (2016), estima-se que a taxa de rotatividade global do emprego formal em Santa Catarina tenha ficado em torno dos $40 \%$ no período em análise. Na modalidade do trabalho parcial, estima-se que essa mesma taxa tenha sido de aproximadamente $50 \%$, e que tenha chegado a $75 \%$ para o trabalho intermitente.
} 
TABELA 7 - SUBGRUPOS DE OCUPAÇÃO COM MAIOR INCIDÊNCIA DE TRABALHO PARCIAL EM SANTA CATARINA (2017-2018)

\begin{tabular}{lccc}
\hline \multicolumn{1}{c}{ Subgrupo } & Saldo Trab. Parcial & Saldo Geral & Parcial/Geral \\
\hline Profissionais do ensino & 3.166 & 2.538 & 1,25 \\
Professores leigos e de nível médio & 128 & 459 & 0,28 \\
Trabalhadores dos serviços & 596 & 5.352 & 0,11 \\
\hline
\end{tabular}

Fonte: RAIS (2019); Elaboração dos autores.

Nota: Principais subgrupos CBO 2002, exceto subgrupos com participação inferior a 1\% no total dos vínculos.

Ao longo de 2018, o subgrupo com maior incidência de trabalho parcial em Santa Catarina foi o dos profissionais de ensino. Nessa categoria, o saldo dos trabalhadores em regime parcial (3.166) foi inclusive superior ao saldo geral de empregos (2.538). Além disso, o trabalho parcial também foi expressivo dentre os professores leigos e de nível médio, abrangendo 128 dos 459 vínculos gerados. Somados, esses dois subgrupos representaram 55\% de todos os trabalhos parciais criados no estado em 2018. Tendo em vista que essas são categorias com reduzidos graus de informalidade, esses resultados indicam que o principal recurso ao trabalho parcial em Santa Catarina não foi para estender direitos aos empregados informais, mas para reduzir os custos com a contratação de trabalhadores em tempo integral, destacadamente os professores de ensino superior ${ }^{19}$.

Nos demais setores, a rigor, a participação do trabalho parcial foi bem mais restrita. Dentre as exceções, vale destacar o subgrupo dos trabalhadores dos serviços, que incorporou 596 trabalhadores parciais em 2018. Esse saldo se deve basicamente à forte adoção dessa modalidade de trabalho nas atividades de administração, conservação e manutenção de edifícios e logradouros.

Por sua vez, o trabalho intermitente foi mais predominante entre os trabalhadores da indústria extrativa e da construção civil. Apesar do baixo número de contratações parciais (166), elas praticamente se equipararam ao saldo total da categoria (172). Dentre as ocupações em que o trabalho intermitente foi mais recorrente, destacam-se pedreiros e ajudantes de obras.

Em seguida, aparecem trabalhadores dos serviços, que registraram o maior saldo de vínculos intermitentes (735) no período, valendo-se de sua posição enquanto subgrupo mais expressivo no mercado de trabalho formal do estado. O trabalho intermitente representou cerca de $8 \%$ das contratações desse subgrupo, com saldos particularmente positivos nos serviços de vigilância, hotelaria e alimentação.

19 Esse fenômeno tem se refletido em diversas manifestações do Sindicado dos Professores do Estado de Santa Catarina, que chegou a denunciar a demissões em massa de professores no período imediatamente posterior à consumação da reforma trabalhista (SINPROESC, 2017). O número de professores do ensino superior em regime parcial no estado passou de 224 para 2.932 entre 2017 e 2018 (RAIS, 2019). 


\section{TABELA 8 - SUBGRUPOS DE OCUPAÇÃO COM MAIOR INCIDÊNCIA DE TRABALHO INTERMITENTE EM SANTA CATARINA (2017-2018)}

\begin{tabular}{lccc}
\hline \multicolumn{1}{c}{ Subgrupo } & $\begin{array}{c}\text { Saldo Trab. Inter- } \\
\text { mitente }\end{array}$ & Saldo Geral & Parcial/Geral \\
\hline $\begin{array}{l}\text { Trabalhadores da indústria extrativa e } \\
\text { construção civil }\end{array}$ & 166 & 172 & 0,97 \\
$\begin{array}{l}\text { Trabalhadores dos serviços } \\
\begin{array}{l}\text { Técnicos de nível médio nas ciências } \\
\text { administrativas }\end{array}\end{array}$ & 735 & 5.352 & 0,14 \\
\hline
\end{tabular}

Fonte: RAIS (2019); Elaboração dos autores.

Nota: Principais subgrupos CBO 2002, exceto subgrupos com participação inferior a 1\% no total dos vínculos.

Por fim, consta ainda o subgrupo dos técnicos de nível médio nas ciências administrativas, que incorporou 170 trabalhadores intermitentes. Ao contrário das duas categorias anteriores, esses profissionais tendem a ser mais especializados, sendo contratados para serviços tipicamente esporádicos, como operações comerciais, de inspeção ou de fiscalização.

\section{CONSIDERAÇÕES FINAIS}

A reforma trabalhista aprovada no Brasil em 2017 se insere em um contexto histórico de flexibilização das relações de trabalho. Nesse sentido, a desestruturação da legislação protetora do trabalho se justifica em premissas que associam a geração de empregos à redução dos custos com trabalho e menos à própria dinâmica de investimentos da economia.

Para demonstrar a falsidade de tais premissas, este artigo traçou um panorama do mercado de trabalho catarinense entre 2014 e 2018, à luz da própria dinâmica econômica nacional. A crise econômica que se instalou no país a partir de 2014 afetou duramente o mercado de trabalho brasileiro, invertendo a tendência do início do século. Acompanhando a tendência nacional, o desemprego cresceu enormemente em Santa Catarina entre 2015 e 2016, muito embora o estado tivesse se mantido com os menores índices de desocupação do país em tal período.

Já a partir de 2017, o mercado de trabalho estadual passou a apresentar alguns sinais de recuperação. Esse comportamento mais dinâmico do emprego catarinense nesse último período pode estar associado às condições prévias à crise, destacando-se os altos índices de formalização das relações trabalhistas e a existência de um sistema econômico regionalizado e bastante diversificado, que impediu efeitos generalizados da crise sobre o mercado de trabalho catarinense.

Considerando-se as categorias de ocupação, observou-se que o período foi marcado por um crescimento acelerado da informalidade. A participação do trabalho por conta própria no total das ocupações subiu de 20,7\%, em 2014, para 22,1\%, em 2018, enquanto a do emprego sem carteira de trabalho assinada passou de $6,9 \%$ para $8,3 \%$, respectivamente. Esse processo derivou da redução dos empregos com carteira, cuja participação no agregado estadual diminuiu em cerca de 3 pontos percentuais entre 2014 e 2017. Foi somente neste último ano que essa categoria voltou a apresentar saldos positivos, contendo o crescimento da informalidade.

Do ponto de vista dos setores de atividade, notou-se que o setor industrial (indústria da transformação, particularmente) foi duramente afetado pela crise econômica, ocasionando uma 
redução de sua participação no conjunto do emprego estadual. Ainda assim, esse setor seguiu sendo muito expressivo no mercado de trabalho catarinense, de modo que sua retomada explica, em grande medida, a incipiente geração de empregos formais observada a partir de 2017. Não obstante, o estado também segue uma tendência nacional de concentração dos empregos nos setores de serviços, os quais ampliaram suas participações no total das ocupações. Tal tendência, como se sabe, é marcada por alta rotatividade, níveis de remuneração reduzidos e pouco acesso à rede de benefícios sociais.

Além disso, a análise revelou um crescimento contínuo e acelerado (24,5\% ao ano) da população subutilizada, de modo que a taxa de subutilização da força de trabalho estadual chegou a $12,3 \%$ em 2018. Tal tendência se manteve ininterrupta desde o ano de 2015, bem como após a aprovação da reforma trabalhista, contrariando o discurso dos defensores da reforma que assinalavam para o sentido oposto.

Tais fatores ainda não são suficientes para imputar a tendência de precarização das relações de trabalho apenas à nova legislação trabalhista. Nesse sentido, parece que a forma mais evidente pela qual a reforma trabalhista vem afetando o mercado de trabalho catarinense diz respeito à intensificação das subocupações, que foram potencializadas com a incorporação dos trabalhos intermitente e parcial. Embora a flexibilidade estrutural do mercado de trabalho brasileiro faça com que a adoção dessas modalidades não seja tão recorrente, chama a atenção o fato de que o saldo dos contratos parciais foi equivalente a cerca de $12 \%$ de todos os vínculos formais de trabalho gerados no estado em 2018, enquanto os contratos intermitentes abrangeram aproximadamente $5 \%$ desses novos vínculos.

A expansão dessas modalidades de trabalho demonstra um dos meios pelos quais a reforma trabalhista pode estar contribuindo para a precarização do mercado de trabalho estadual. Ainda que o salário/hora de um trabalhador parcial ou intermitente seja semelhante ao dos demais empregados, a renda total auferida tende a ser insuficiente, ao se situar, em geral, muito próxima do valor do salário mínimo. Além disso, a precarização é fomentada pela instabilidade dessas formas de contratação, associada ao limite do acesso, por parte desses trabalhadores, à rede de benefícios sociais, comparativamente aos demais trabalhadores com relações formalizadas integrais.

O crescimento mais expressivo do trabalho parcial se deve especialmente à sua adoção pelas instituições privadas de ensino superior, sendo, portanto, uma forma de suprimir direitos trabalhistas já consolidados e não de estender esses direitos aos trabalhadores mais vulneráveis. Já o trabalho intermitente não foi amplamente adotado por nenhum setor da economia, mas o caráter das ocupações em que essa modalidade foi mais predominante indica que, por um lado, ela pode estar sendo utilizada para formalizar vínculos de trabalho majoritariamente precários - a exemplo dos trabalhadores da construção civil -, e, por outro lado, para reduzir os custos com empregados formais de serviços mais esporádicos - como os de fiscalização, inspeção etc.

Assim, é possível concluir que a reforma trabalhista, em vez de atacar a precarização do trabalho, acabou facilitando sua extensão para áreas que antes tinham algum tipo de segurança. Mesmo reconhecendo as desigualdades existentes, a nova legislação acabou legitimando e estimulando a lógica da flexibilização das relações trabalhistas, caminho desejado pelo capital para ampliar suas taxas de lucro, em detrimento dos interesses da classe trabalhadora. Neste diapasão, o discurso dos vencedores procura separar os segmentos dos excluídos pelo cinismo de que é impossível atender a todos devido ao excesso de direitos de uma minoria privilegiada. 


\section{REFERÊNCIAS}

BALTAR, Paulo. Política econômica, emprego e política de emprego no Brasil. Estudos Avançados, São Paulo, v. 28, n. 81, mai./ago. 2014.

BCB. BANCO CENTRAL DO BRASIL. Portal de Dados Abertos. 2019. Disponível em: https://dadosabertos.bcb.gov.br. Acesso em: 28 abr. 2021.

BIAVASCHI, M. B. et al. O impacto de algumas reformas trabalhistas na regulação e nas instituições públicas do trabalho em diálogo comparado. In: KREIN, J. D.; GIMENEZ, D. M.; SANTOS, A. L. (orgs.). Dimensões Críticas da Reforma Trabalhista. Campinas: IE Unicamp, 2018. p. 209-242.

BRAGA, Ruy. A Política do Precariado: do populismo à hegemonia lulista. 1 ed. São Paulo: Boitempo, 2013.

CAGED. CADASTRO GERAL DE EMPREGADOS E DESEMPREGADOS. Programa de disseminação das estatísticas do trabalho. 2019. Disponível em: bi.mte.gov.br/bgcaged/rais. php. Acesso em: 29 abr. 2021.

CESIT. CENTRO DE ESTUDOS SINDICAIS E ECONOMIADO TRABALHO. Contribuição Crítica à Reforma Trabalhista. Campinas: IE Unicamp, 2017.

DIEESE. DEPARTAMENTO INTERSINDICAL DE ESTATÍSTICA E ESTUDOS SOCIOECONÔMICOS. Rotatividade no mercado de trabalho brasileiro. São Paulo: DIEESE, 2016.

FILGUEIRAS, V.; BISPO, B.; COUTINHO, P. A reforma trabalhista como reforço a tendências recentes no mercado de trabalho. In: KREIN, J. D.; GIMENEZ, D. M.; SANTOS, A. L. (orgs.). Dimensões Críticas da Reforma Trabalhista. Campinas: IE Unicamp, 2018. p. 125-154.

HARVEY, David. Do Fordismo à Acumulação Flexível. In: HARVEY, David. Condição PósModerna: Uma pesquisa sobre as origens da mudança de cultura. São Paulo: Loyola, 2012. p. 135-184.

IBGE. INSTITUTO BRASILEIRO DE GEOGRAFIA E ESTATÍSTICA. PIM-PF - Pesquisa Industrial Mensal, Produção Física. 2019. Disponível em: https://sidra.ibge.gov.br/pesquisa/ pim-pf-brasil/tabelas. Acesso em: 29 abr. 2021.

PNADC/T - Pesquisa Nacional por Amostra de Domicílios Contínua

Trimestral. 2019. Disponível em: sidra.ibge.gov.br. Acesso em: 29 abr. 2021.

KREIN, J. D. et al. Flexibilização das relações de trabalho: insegurança para os trabalhadores. In: KREIN, J. D.; GIMENEZ, D. M.; SANTOS, A. L. (orgs.). Dimensões Críticas da Reforma Trabalhista. Campinas: IE Unicamp, 2018. p. 95-122.

MARINHO, Rogério. Relatório da Comissão Especial destinada a proferir parecer ao Projeto de Lei no 6.787, de 2016, do Poder Executivo, 2016. Disponível em: goo.gl/nQ4V6K. Acesso em: 29 abr. 2021.

MATTEI, L.; HEINEN, V. L. Panorama do mercado de trabalho brasileiro entre 2012 e 2018. In: SEP. XXIV ENEP: Anais do XXIV ENCONTRO NACIONAL DE ECONOMIA POLÍTICA. Vitória, UFES, 2019. Disponível em: https:/sep.org.br/anais/2019/SessoesOrdinarias/Sessao4.Mesas31_40/Mesa35/352.pdf. Acesso em: 29 abr. 2021.

MATTEI, L.; HEINEN, V. L.; FRONZA, M. V. Evolução e distribuição dos vínculos formais de trabalho nas mesorregiões de Santa Catarina entre 2001 e 2017. In: XIII Encontro de 
Economia Catarinense, 2019, Criciúma. Anais do XIII ENCONTRO DE ECONOMIA CATARINENSE. Blumenau: APEC, 2019. v. 1. p. 185-209.

OSORIO, Jaime. Padrão de reprodução do capital: uma proposta teórica. In: FERREIRA, C.; OSORIO, J.; LUCE, M. (orgs.). Padrão de reprodução do capital: Contribuições da teoria marxista da dependência. São Paulo: Boitempo, 2012, p. 37-86.

RAIS. RELAÇÃO ANUAL DE INFORMAÇÕES SOCIAIS. Programa de disseminação das estatísticas do trabalho. 2019. Disponível em: bi.mte.gov.br/bgcaged/rais.php. Acesso em: 29 abr. 2021.

SEF/SC. SECRETARIA DE ESTADO DA FAZENDA DE SANTA CATARINA. Indicadores Econômico-Fiscais. 2019. Disponível em: http://sde.sc.gov.br/index.php/biblioteca/ boletim/1035--352/file. Acesso em: 29 abr. 2021.

SINPROESC. SINDICADO DOS PROFESSORES DO ESTADO DE SANTA CATARINA. Um Tsunami de Demissões. 2017. Disponível em: bit.ly/2yzc0jy. Acesso em: 29 abr. 2021. 